\title{
O Candombe do Açude Cipó e a resistência cultural quilombola: lutas contra-hegemônicas de um Sul multifacetado
}

\author{
El Candombe del Açude Cipó y la resistencia cultural afrodescendiente: \\ luchas contra-hegemónicas de un Sur multifacético
}

\section{The Açude Cipó 's Candombe and the afrodescendant cultural resistance: counter-hegemonic struggles from a multifaceted South}

\author{
Maria do Rosário Gomes da Silva ${ }^{1}$
}

\begin{abstract}
Resumo
Este trabalho parte da perspectiva descolonial para refletir sobre o festejo do Candombe celebrado na comunidade afrodescendente Açude Cipó, localizada no Parque Estadual Serra do Cipó, em Minas Gerais. Esta manifestação cultural será abordada a partir de pesquisa qualitativa baseada em observação direta e entrevistas semiestruturadas, tendo como principais referenciais teóricos os conceitos de racionalidade estético-expressiva e resistência contra-hegemônica. Enquanto a noção de racionalidade estético-expressiva nos possibilita reconhecer o potencial emancipatório dos elementos efusivos, lúdicos e dilemáticos presentes na cultura da festa, a ideia de contra-hegemonia nos permite compreender as formas de luta que atuam no âmbito das disputas pelas reconfigurações simbólicas que buscam dar visibilidade aos modos de vida, identidades e crenças que habitam um Sul invisibilizado pelos padrões de um projeto moderno binarista e eurocêntrico. A partir de tal aporte teórico, pretende-se refletir sobre as formas de resistência que emergem das subjetividades multifacetadas do Candombe quilombola que, ao abrirem novos horizontes epistemológicos, também apontam para outras possibilidades de luta social.
\end{abstract}

Palavras-Chave: Candombe; resistência quilombola; cultura festiva; perspectiva descolonial.

\section{Resumen}

Este trabajo se propone a analizar, desde una perspectiva descolonizadora, la fiesta del Candombe de la comunidad afrodescendiente Açude Cipó, ubicada en lo Parque Estadual Serra do Cipó, en Minas Gerais. Se estudiará esta manifestación cultural a partir de una investigación cualitativa basada en observación directa y entrevistas parcialmente estructuradas, utilizando las referencias teóricas de los conceptos de racionalidad estético-expresiva y resistencia contra-hegemónica. Mientras la noción de racionalidad estético-expresiva nos permite reconocer el potencial emancipador de los elementos efusivos, lúdicos y dilemáticos presentes en la cultura de la fiesta, la idea de contra-hegemonía nos posibilita comprender los modos de lucha que operan no ámbito de las disputas pelas reconfiguraciones simbólicas que buscan dar visibilidad a los modos de vida, identidades y creencias que habitan un Sur ocultado por los patrones de un proyecto moderno binario e eurocéntrico. Desde esta base teórica, se pretende reflexionar sobre los modos de resistencia que emergen de las subjetividades multifacéticas del Candombe e sus nuevos horizontes epistemológicos que señalan otras posibilidades de lucha social.

Palabras Claves: Candombe; resistencia afrodescendiente; cultura festiva; perspectiva descolonizadora.

\footnotetext{
${ }^{1}$ Mestre em Ciência Política; Universidade Federal de Minas Gerais - UFMG; Belo Horizonte, Minas Gerais, Brasil; maria.mrgs@gmail.com. Trabalho apresentado no I Seminário Latino-Americano de Estudos em Cultura - SEMLACult, Foz do Iguaçu/PR, Brasil, 2017.
} 


\begin{abstract}
This work starts from the decolonial perspective to reflect about the Candombe celebration realized in the afrodescendant community Açude Cipó, located in the Parque Estadual Serra do Cipó, in Minas Gerais. This cultural manifestation will be approached from a qualitative research based on direct observation and semistructured interviews, having as main theoretical references the concepts of expressive-aesthetic rationality and counter-hegemonic resistance. While the notion of aesthetic-expressive rationality enables us to recognize the emancipatory potential of effusive, playful and dilemmatic elements present in the festivity culture, the idea of counter-hegemony allows us to understand the forms of struggle that operate within the framework of disputes over symbolic reconfigurations that seek to give visibility to the ways of life, identities and beliefs that inhabit a South made invisible by the standards of a binary and Eurocentric modern project. From this theoretical contribution, it's intended to reflect on the forms of resistance that emerge from the multifaceted subjectivities of the Candombe that open new epistemological horizons as they also point to other possibilities of social struggle.
\end{abstract}

Keywords: Candombe; afrodescendant resistance; festivity culture; decolonial perspective.

\title{
1. Introdução
}

O mundo é muito mais amplo, diversificado e repleto de possibilidades emancipatórias do que aquilo que a tradição científica ocidental conhece e considera como válido. Conforme Santos (2002) analisa, a modernidade padece do chamado desperdício das experiências sociais disponíveis, uma vez que se estabeleceu a partir de um pensamento eurocêntrico que, ao se tornar hegemônico, cristalizou o modelo racional fundado no contexto das revoluções industriais, do desenvolvimento capitalista, do imperialismo e do colonialismo. Um modelo que, ao legitimar apenas as manifestações da razão instrumental lógico-discursiva, relegou à invisibilidade e descrédito todas aquelas práticas, conhecimentos e lutas que habitam um Sul barroco, dilemático e multifacetado (SANTOS, MENESES; 2010).

Partindo de tal perspectiva crítica descolonial, propõe-se uma reflexão sobre a cultura festiva do Candombe mineiro. Herdeiro da tradição do tambor Banto, o Candombe incorpora elementos do catolicismo negro de confraria às práticas percussivas africanas, dando vida a uma celebração caracterizada pela forma singular de unir canto, dança, reza e narrativas poéticas do passado. Um festejo que nasceu como manifestação típica dos quilombos que surgiram na região de Minas Gerais entre o século XVIII e XIX enquanto territórios criminalizados e fortemente reprimidos pelas autoridades coloniais e imperiais. Os quilombos brasileiros representaram, por séculos, espaços de refúgio e resistência ao regime escravista (CAMPOS, 2005), e, atualmente, as comunidades quilombolas ou comunidades remanescentes de quilombos ${ }^{2}$, abarcam grupos sociais diversificados que descendem das chamadas comunidades negras rurais ou terras de preto (ARRUTI, 1997).

\footnotetext{
${ }^{2}$ Conforme definição presente no texto da Constituição Federal de 1988.
} 
Neste trabalho, estudaremos o Candombe festejado pela comunidade quilombola Açude Cipó - uma das herdeiras mais antigas da tradição candombeira existente na região metropolitana de Belo Horizonte. Localizado na área rural de Jaboticatubas, nas proximidades do Parque Estadual da Serra do Cipó, o quilombo do Açude foi fundado no final do século XVIII como espaço de refúgio para os escravos oriundos da fazenda Cipó Velho que ali se abrigavam contra capatazes, capitães do mato e forças policiais (CEDEFES, 2008, p. 177). Mesmo após o fim do regime escravista, a comunidade permaneceu enfrentando conflitos de terras com fazendeiros de toda a região do entorno do rio Cipó até o final da década de 1990, tendo obtido em 2006 o certificado de reconhecimento da Fundação Cultural Palmares ${ }^{3}$ e conquistado para todas as famílias o título legal de posse das terras herdadas de seus antepassados.

Formado por 22 famílias e ocupando uma área de aproximadamente $11.000 \mathrm{~m}^{2}$, o Açude Cipó sobrevive através de hortas comunitárias e trabalhos urbanos e rurais realizados nas pousadas e localidades próximas (CEDEFES, Projeto Açude Cipó). No quilombo não existem escolas, postos de saúde ou qualquer tipo de investimento público e as atividades turísticas da região, nas últimas décadas, deram certa visibilidade às tradições e festejos típicos do lugar (TRINDADE, 2011). Uma das figuras mais emblemáticas do Açude é a matriarca "dona Mercês", que exerce um papel de liderança fundamental para a união e preservação da comunidade, além de representar uma fonte das memórias do passado que continuam sendo repassadas oralmente para as novas gerações. Sendo neta de uma das primeiras famílias que se refugiaram no Açude, ela mantém vivos os ensinamentos dos seus antepassados e uma história de resistência na qual, a luta pela liberdade, sempre andou lado a lado da luta pela preservação de uma identidade quilombola profundamente enraizada na cultura festiva do Candombe.

A partir de tal experiência festiva do Açude pretende-se, portanto, analisar os elos que aproximam a manifestação cultural do Candombe das lutas simbólicas quilombolas contra a invisibilização e estigmatização de seus modos de vida, identidades e crenças. Tal abordagem qualitativa será desenvolvida através de estratégias metodológicas baseadas em observação direta e entrevistas semiestruturadas ${ }^{4}$, contando inicialmente com uma breve contextualização histórica do Candombe quilombola, seguida de uma discussão sobre os dois principais eixos

\footnotetext{
${ }^{3}$ A Fundação Cultural Palmares (FCP) é uma instituição pública voltada para a promoção e preservação da cultura afro-brasileira, sendo responsável pela formalização da existência das comunidades quilombolas e por sua assessoria jurídica. Cf. http://www.palmares.gov.br/.

${ }^{4} \mathrm{Tal}$ abordagem deriva da pesquisa desenvolvida na dissertação de mestrado "O potencial emancipatório das festas do tambor mineiro: a dimensão dionisíaca de um Atlântico Negro invisível" (Programa de Pós-graduação em Ciência Política, Universidade Federal de Minas Gerais, 2014).
} 
conceituais utilizados para a análise - as noções de racionalidade estético-expressiva e resistência contra-hegemônica (SANTOS 2002, 2010). Por fim, a partir de tais aportes, analiso o Candombe da comunidade Açude Cipó buscando identificar tanto os elementos estéticos, performáticos e lúdicos que desestabilizam relações culturais opressoras herdadas do passado colonial e escravista, quanto as formas de resistência e emancipação social gestadas nas reconfigurações simbólicas que, ao proporem novas abordagens da realidade, abrem caminho para outros mundos possíveis.

\section{O Candombe mineiro e a resistência quilombola: a luta contra a exclusão em todas as suas dimensões}

A palavra Candombe é usada para denominar as danças e práticas percussivas tradicionais dos Bantos, povos originários da região ocidental do continente africano. Um vocábulo que deriva do termo Kandombile ${ }^{5}$, utilizado pelos Bantos como referência às formas de culto religioso centradas na figura do tambor como ente simbólico responsável por fazer a ponte entre homens e deuses (SLENES, 1992). Espalhada por inúmeras regiões americanas durante os séculos de regime escravista e tráfico negreiro, a tradição do tambor Banto pode ser encontrada ao longo de todo o Atlântico desde o período colonial, quando inúmeros relatos de viajantes já descreviam as grandes semelhanças observadas entre os tambores encontrados no Congo do século XVI com os tambores yuka de Cuba, os cumina da Jamaica, os cumacos do litoral da Venezuela e os atabaques do Uruguai (FERREIRA, 2006).

Uma tradição percussiva, que, embora associada a práticas de diferentes grupos étnicos e a contextos históricos variados, compartilha uma mesma matriz linguística e possui muitos traços culturais e significados religiosos em comum (CRAEMER et al., 1976, p. 460). No Brasil, tal tradição deu origem às chamadas celebrações do batuque Congo-Angolês, classificadas por Carneiro (1974) dentro de um amplo complexo nacional formado por 30 diferentes práticas culturais encontradas ao longo de 11 Estados do país. Nesta classificação, além do Candombe mineiro propriamente dito, estão incluídas manifestações como o Tambor de crioula maranhense, o Jongo capixaba, a Sussa goiana, o Samba de Roda do Recôncavo Baiano e o Samba de Aboio sergipano. Todas elas possuem em comum características típicas das celebrações do tambor Banto como a utilização do sistema rítmico de chamadas e respostas entre solistas e coro, o recurso à improvisação sob a forma de versos melódicos e a

\footnotetext{
${ }^{5}$ O termo Kamdombile significa "ação de rezar" e também deu origem à palavra candomblé (SLENES, 1992, p.49).
} 
realização de coreografias em roda que intercalam dança, canto e desafios poéticos.

Tais características, no caso específico do Candombe mineiro, dão vida ao encontro cultural da tradição do tambor Banto com o catolicismo negro de confraria, gerando uma celebração festiva do sincretismo religioso que uniu ritos africanos a referências simbólicas do cristianismo português. Sendo considerado o pai do Congado, do Jongo e das Folias existentes em todo o sudeste do Brasil, o festejo do Candombe nasceu das celebrações conhecidas como festas de terreiro ou batuques dos negros (DIAS, 2009). Estas celebrações eram presentes, sob diversas formatações e estilos, em inúmeras senzalas brasileiras durante todo o regime escravista ${ }^{6}$, sendo normalmente realizadas em datas comemorativas como dias de santos, feriados e finais de colheitas (TINHORAO, 1988, p. 29-30). Embora tenham sido, por séculos, reprimidas e descritas pejorativamente por fazendeiros e autoridades locais como "rituais pagãos", “danças imorais" e "diversão desonesta” (SARMENTO, 1880), a eventual permissão para sua realização era utilizada como meio de reduzir o risco de fugas em massa e rebeliões de escravos.

Assim como nas festas de terreiro, o festejo do Candombe é conduzido por tambores feitos de troncos de árvores e peles de animais curtidas nas fogueiras, sendo conhecidos tradicionalmente como tambus sagrados e, em algumas localidades, nomeados de Santana, Santaninha e Chama (ARAUJO, QUEIROZ; 2014). Seguindo os mesmos rituais tradicionais de preparação e disposição dos tambus, os candombeiros iniciam as festividades fazendo reverências aos santos protetores e ancestrais, estabelecendo um sistema rítmico de chamadas e respostas entre os percussionistas e o coro que, juntos, vão entoando os pontos ${ }^{7}$ e executando gestos coreográficos que variam de velocidade e intensidade à medida que a celebração avança. Em sua formação original, todos os cantos e danças são realizados numa grande roda formada em torno dos tambus, intercalando momentos sagrados e lúdicos nos quais os participantes, em linguagem metafórica, fazem narrativas das mazelas do tempo da escravidão, das memórias dos antepassados, das lutas contra fazendeiros e capatazes e das lembranças de uma África perdida para a diáspora forçada.

A origem do festejo do Candombe costuma ser atribuída ao final do século XVIII, na região de Minas Gerais. Ele se tornou uma manifestação característica das comunidades afrodescendentes que se constituíam como espaços de refúgio e resistência contra a

\footnotetext{
${ }^{6}$ O período escravista no Brasil vai de 1530 a 1888, quando é assinada a Lei Áurea pela princesa Isabel.

${ }^{7}$ No Candombe, assim como em diversas celebrações do tambor Banto existentes no Brasil, os pontos são os versos melódicos improvisados por solistas que têm como resposta o refrão cantado pelos participantes da roda.
} 
escravidão - os quilombos, também conhecidos como mocambos ou terras de preto (CAMPOS, 2005). As primeiras referências aos quilombos no Brasil surgem no contexto da repressão da Coroa Portuguesa às formas de habitação descritas como espaços distantes da povoação "onde se encontrassem acima de quatro negros, com ranchões, pilões e de modo de aí se conservarem" (GUIMARÃES, 1988, p. 131). Espaços fundados por aqueles que conseguiam escapar do sistema escravista e formavam coletividades paralelas que se tornavam territórios criminalizados e duramente combatidos por proprietários de terras, forças policiais e autoridades locais. Os negros aquilombados e seus descendentes eram percebidos como forte ameaça a um regime escravista que temia o estímulo a fugas e rebeliões, sendo alvo de perseguições e penalizações violentas (ALMEIDA, 2002).

De acordo com o Centro de Documentação Eloy Ferreira da Silva ${ }^{8}$, existem atualmente cerca de 400 quilombos em Minas Gerais, presentes em diversas regiões do Estado e abrangendo aproximadamente 150 municípios $^{9}$. Eles integram uma história comum aos territórios quilombolas brasileiros que permaneceram reprimidos e criminalizados durante todo o período escravista, para depois padecerem da invisibilidade legada por um modelo abolicionista puramente legalista que, após a libertação tardia, acabou por lançar os escravos e seus descendentes à sua própria sorte (BOSI, 1992, p. 266). Conforme Bosi (1992) analisa, trata-se de uma abolição que atou liberalismo e preconceito de forma tal, que tornou a libertação dos escravos um passo para uma nova realidade de opressão marcada pelas limitadas oportunidades de inserção social e econômica durante as quatro décadas que seguiram a abolição - uma nova etapa da exclusão histórica da população afrodescendente no Brasil na qual não vai existir qualquer menção na legislação nacional que redefina a categoria quilombo ou que procure abordar os desdobramentos de sua existência marginalizada (GOMES, 2009).

Esse longo tempo de silêncio será rompido apenas com a Constituição Federal de 1988, quando será reconhecido o direito à propriedade definitiva aos remanescentes das comunidades dos quilombos, estabelecendo assim o marco jurídico-formal do direito à propriedade quilombola no país. Ele foi incluído no texto constitucional através do Artigo 68 do Ato das Disposições Constitucionais Transitórias (ADCT) e, posteriormente, regulamentado pelo Decreto Presidencial 4.887/2003 que definiu o procedimento para a “identificação, reconhecimento, delimitação, demarcação e titulação das terras ocupadas por

\footnotetext{
${ }^{8}$ Cf.: http://www.cedefes.org.br/.

${ }^{9}$ Entre eles, podemos citar: Contagem, Brumadinho, Belo Vale, Januária, Bias Fortes, Paraopeba, Viçosa, Ressaquinha,Vazante, Muzambinho, entre tantos outros. Fonte: http://www.palmares.gov.br.
} 
remanescentes das comunidades de quilombos". A conquista deste direito foi o resultado das reivindicações dos Movimentos Sociais Negros aliados às lideranças das comunidades quilombolas, que, ao agregarem novos tipos de questões à luta política afrodescendente no Brasil, levaram à criação do Movimento Quilombola e à construção de uma agenda própria ligada à luta pelo direito ao reconhecimento, redistribuição e representação política (GOMES, 2009, p. 18-19).

Assim como os quilombos brasileiros seguem lutando contra a exclusão em todas as suas dimensões, o festejo do Candombe permanece resistindo contra o silenciamento e a discriminação de modos de vida, identidades e crenças revividas e reverenciadas através dos seus pontos, danças e cantos. Uma cultura festiva que preserva versões de mundo e conhecimentos que ainda padecem do referido desperdício de um olhar ocidental que não reconhece aquilo que não pode ser reduzido às dicotomias e fronteiras rígidas de um modelo racional hegemônico instaurado a partir de cisões, negações e hierarquizações (SANTOS, 2002). Seus elementos lúdicos, performáticos e efusivos representam, portanto, um verdadeiro desafio aos sentidos que nos convidam a uma concepção ampliada do racional, da resistência política e da própria emancipação social que, ao possibilitar novas perspectivas libertas das amarras cognitivas e epistemológicas herdadas da lógica colonial, abra caminho para novas formas de abordagem do real pensadas a partir de outras bases.

\section{A cultura festiva e os novos olhares do Sul para o Sul: da racionalidade estético- expressiva à resistência contra-hegemônica}

A cultura festiva do Candombe mineiro traz à tona perspectivas descoloniais que transcendem a lógica binarista e eurocentrada de um padrão racional que, sob as mais diversas formas, incorpora e cristaliza uma forma de conhecimento que tem sido hegemônica tanto no plano científico quanto filosófico há, pelo menos, dois séculos no Ocidente (QUIJANO, 2005). Ele remonta à revolução científica do século XVI ocorrida no âmbito das ciências naturais e, posteriormente, durante os séculos XVIII e XIX, incorporada às ciências sociais através de uma teoria racional do mundo baseada na primazia do logos em detrimento ao mundo sensível (ESCOBAR, 2003). Tal perspectiva dicotômica, ao longo do processo de consolidação do Estado moderno, gerou a marginalização daqueles elementos efusivos, lúdicos e performáticos, que, enquanto vinculados à dimensão da corporalidade e do mítico, não puderam ser encaixados num modelo racional que elegeu a linguagem lógico-discursiva como única fonte legítima de acesso ao conhecimento e de produção científica. 
Um modelo que se sobrepôs às demais formas de acesso ao conhecimento e subalternizou inúmeros saberes, experiências e práticas ligadas à esfera da cultura, da arte e da festa - as chamadas manifestações da racionalidade estético-expressiva (SANTOS, 2002, p.78). Elas se enquadram numa concepção pós-colonial de recorte culturalista que encontra nas práticas performativas, na oralidade e nos sistemas de representação as chaves de compreensão de um Sul global ${ }^{10}$ efusivo, dilemático e multifacetado (MENESES, 2008). Para pensar as formas de luta, organização social e produção de conhecimento que emergem deste Sul diversificado e complexo, Santos (2010) propõe uma perspectiva pós-colonial que pode ser pensada a partir de dois eixos:

\begin{abstract}
$\mathrm{Na}$ primeira acepção, o pós-colonialismo traduz-se num conjunto de análises econômicas, sociológicas e políticas sobre a construção dos novos Estados, a sua base social, a sua institucionalidade e a sua inserção no sistema mundial, as rupturas e as continuidades com o sistema colonial, as relações com a ex-potência colonial e a questão do neocolonialismo, as alianças regionais, etc. Na segunda acepção, o póscolonialismo tem um recorte culturalista, insere-se nos estudos culturais, linguísticos e literários e usa privilegiadamente a exegese textual e as práticas performativas para analisar os sistemas de representação e os processos identitários (SANTOS, 2010, p. 233-234).
\end{abstract}

Nesta segunda acepção temos, então, uma forma de pensar os processos identitários ancorados em tradições culturais que, assim como o Candombe, mobilizam dimensões estéticas e expressivas como possibilidades criativas de sobrevivência e preservação de versões de mundo negadas ou produzidas como inexistentes pelo pensamento colonial. Desta forma, ela remete à racionalidade estético-expressiva enquanto fonte de resistência alternativa que teria se desenvolvido como versão subalternizada de lutas políticas e práticas sociais invisibilizadas por uma revolução científica que, ao ocorrer em paralelo com a crença na supremacia da raça branca, fez do suposto triunfo da modernidade a verdadeira negação ao resto da humanidade da própria capacidade de pensar (MIGNOLO, 2003, p. 634). Um triunfo que gerou o então desperdício das múltiplas experiências sensoriais, artísticas e culturais que nasceram nas margens de um modelo de pensamento etnocêntrico que se estruturou a partir de exclusões e cisões.

Santos (2002) analisa o processo pelo qual a racionalidade estético-expressiva teria sido, ao longo da história de consolidação do projeto moderno, invadida pela racionalidade cognitivo-instrumental baseada no pensamento lógico-discursivo como forma de

\footnotetext{
${ }^{10}$ Seguindo a definição de Santos e Meneses (2010), este trabalho concebe o Norte e o Sul como metáforas que nascem do capitalismo e das relações coloniais. Embora, em alguma medida, o Norte e o Sul metafóricos e geográficos possam coincidir, é importante salientar que este alinhamento é apenas parcial e fluido.
} 
conhecimento superior, isolada e intocável. A partir deste processo, teria se instaurado a predominância de uma matriz científica utilitária que se sobrepôs às outras formas de racionalidade existentes como a prático-moral, oriunda do direito e das teorias da justiça, e a estético-expressiva, vinculada aos conceitos de prazer, autoria e artefactualidade discursiva (SANTOS, 2002, p. 74). É nessa sobreposição baseada na hipercientificização e na mercadorização da ciência que este autor contextualiza a marginalização da racionalidade estético-expressiva enquanto esfera do lazer, do prazer e da utopia - dimensões excluídas do projeto moderno e do seu racionalismo científico.

Tal marginalização, no entanto, teria possibilitado uma espécie de semiliberdade a esta forma de racionalidade que, calcada na dimensão fluida e multifacetada da esfera cultural, teria sobrevivido como forma inacabada da modernidade, permanecendo continuamente aberta a novas ressignificações, adaptações e possibilidades criativas. Nesse sentido, na racionalidade estético-expressiva poderíamos encontrar uma fonte de resistência à hegemonia da racionalidade cognitivo-instrumental que teria sobrevivido precisamente nas epistemologias de fronteira que, enquanto tais, subverteram os tradicionais cânones que separam cultura e ciência, estética e ética, arte e política (GROSFOGUEL, 2008). Entre vários outros fatores, isso pode ter contribuído para que as formas estético-expressivas pudessem apresentar maior resistência à dominação do cientificismo ocidental, preservando versões de mundo alternativas aos padrões dualistas legados pela lógica colonial.

Este movimento de resistência presente na própria história das manifestações ligadas à racionalidade estético-expressiva envolve, por sua vez, todos aqueles elementos celebrativos e performáticos que foram sistematicamente excluídos do projeto moderno como versões primitivas vinculadas a tudo aquilo que o colonizador não desejava ser e atribuía ao "outro" colonizado como evidências de selvageria e subdesenvolvimento (COSTA, 2006, p. 86). São estes elementos, no entanto, que garantiram a sobrevivência da subjetividade lúdica que preserva o prazer do jogo, do lazer e da festa entre os seres humanos. É precisamente nesta capacidade de celebração do prazer que emana a força lúdica que resiste à dominação de uma colonização que não é apenas política ou econômica, mas também epistêmica (MIGNOLO, 2003). Em outras palavras:

A colonização do prazer na modernidade ocidental deu-se através da industrialização do lazer e dos tempos livres, das indústrias culturais e da ideologia e prática do consumismo. Contudo, fora do alcance da colonização, manteve-se a irredutível individualidade intersubjetiva do homo ludens, capaz daquilo que Barthes chamou jouissance, o prazer que resiste ao enclausuramento e difunde o jogo entre os seres humanos. Foi no campo da racionalidade estético-expressiva que o prazer, 
apesar de semi-enclausurado, se pôde imaginar utopicamente mais do que semiliberto (SANTOS, 2002, p. 76).

É nesta esfera do prazer semienclausurado que encontramos, portanto, a intersubjetividade do homo ludens como via de resistência a uma colonização que também se consolida pelo controle das formas de lazer, de prazer e dos tempos livres. Através do festivo, do efusivo e do performático, esta força lúdica nos leva ao âmago de processos emancipatórios profundamente enraizados em tradições culturais, manifestações artísticas e celebrações religiosas que resistiram e continuam resistindo contra a colonização de seus modos de vida, identidades e saberes. Elas representam aquelas formas de luta contrahegemônicas $^{11}$ que, a partir da recodificação das relações culturais, buscam gerar novas comunidades interpretativas (RANCIÈRE, 2004) a partir do compartilhamento de um mundo sensível que reconfigura as bases simbólicas das relações de poder - relações estas gestadas na esfera da representação enquanto criadora de significados culturais e produtora do senso comum (HALL, 1997).

Deste modo, tais lutas contra-hegemônicas representam um fenômeno político caracterizado pela resistência contra os monopólios interpretativos do real, isto é, sobre as visões de mundo hegemônicas nas quais se pautam as relações sociais assim como as práticas políticas modernas. A ideia de contra-hegemonia surge, assim, como uma possibilidade de se pensar as lutas políticas que são travadas no âmbito das disputas pelas possibilidades de interpretação da realidade a partir de novos referenciais simbólicos que contestam e reconfiguram as formas de supremacia cultural - formas estas que criam concepções aparentemente coerentes da realidade a partir de homogeneidades ilusórias e hierarquias tácitas (GRAMSCI, 1987). Nesse sentido é que Hall (1997) argumenta que as lutas pela transformação social se travam necessariamente dentro da esfera das relações culturais, se referindo sempre às alterações das configurações do poder cultural como forma de redefinição das estruturas cognitivas que sustentam os poderes hegemônicos.

Trata-se de uma concepção de luta política que parte da premissa de que tanto a escolha quanto a crítica a uma determinada concepção de mundo são fatos políticos relevantes para a constituição das relações de poder sob as quais se estruturam a sociedade e seus atores. Desta forma, estas lutas operam através da competição entre visões de mundo que buscam

\footnotetext{
${ }^{11}$ A noção de hegemonia é um conceito elaborado na obra Teoria da Hegemonia, de Antônio Gramsci (1987). Gramsci utiliza este conceito para nomear a capacidade de direção moral e intelectual que uma classe dominante (ou aspirante a dominante) adquire através da conquista do consenso e da legitimidade perante a maioria da população (BOBBIO et al., 1998, p. 579-580).
} 
provocar mudanças na balança de poder cultural, gerando um deslocamento de sentidos que transforma as capacidades que reproduzem o poder opressor em capacidades que o destroem (SANTOS, 2002, p. 250). Portanto, se o suporte da dominação encontra-se precisamente na capacidade de obscurecer uma perspectiva de mundo pensada sobre bases alternativas, culturas festivas como o Candombe quilombola representam a possibilidade de lançarmos um novo olhar para o Sul desde o Sul - isto é, de abordarmos as vivências, resistências e saberes marginalizados pela lógica colonial a partir de suas fontes estético-expressivas historicamente invisibilizadas e estigmatizadas.

\section{A resistência contra-hegemônica do Candombe do Açude Cipó: reconfigurações simbólicas da origem, da escravidão e da fé}

No Candombe do quilombo Açude Cipó, as 22 famílias residentes e as centenas de visitantes se reúnem num grande terreiro nos fundos da casa da matriarca Maria das Mercês, mais conhecida como "dona Mercês". A festa acontece anualmente sempre no segundo sábado de setembro e celebra, durante doze horas ininterruptas, orações, danças e cantos em louvor a Nossa Senhora do Rosário, considerada a mãe do Candombe e padroeira da comunidade. Herdeiro do sincretismo religioso que uniu a tradição do tambor Banto com referências simbólicas do catolicismo, o festejo combina momentos variados que vão desde cortejos, rodas de capoeira e rezas nas portas das casas, até o hasteamento da bandeira da santa padroeira, a confraternização em torno das ceias servidas com as comidas e bebidas típicas do lugar e a formação da roda em torno das caixas percussivas centenárias - os tambus sagrados. Mantendo a tradição candombeira, o festejo é conduzido pelos mesmos tambus confeccionados pelos primeiros moradores do quilombo, há mais de duzentos anos, a partir de madeira escavada do tronco do saboeiro e coberta com couro de boi.

Após serem afinados na fogueira, os tambus dão vida a um sistema rítmico de chamadas e respostas que conduz os versos melódicos e passos coreográficos dos participantes. Alternando entre solistas (que ocupam o centro da roda) e o coro (formado pela roda), eles realizam um diálogo performático-musical através da improvisação de pontos que, ao serem cantados e dançados, misturam narrativas poéticas do passado com desafios, brincadeiras e jogos que envolvem todos os presentes ${ }^{12}$. Uma celebração do efusivo e do lúdico que faz da roda do Candombe um espaço em que podemos identificar elementos de

\footnotetext{
${ }^{12}$ A comunidade do Açude abre espaço para que os visitantes também entoem seus pontos como solistas e participem ativamente da roda do Candombe. Apenas a atividade de tocar os tambus é restrita aos membros da comunidade.
} 
uma racionalidade estético-expressiva (SANTOS, 2002) que retoma o passado para celebrar o presente, trazendo à tona o arquétipo de um homo ludens cuja força transgressora se encontra justamente na inversão da chave que faz da alegria uma força emancipatória:

\author{
Bate tambô, bate tambô. \\ Hoje é dia de alegria. \\ Hoje é dia de alegria. \\ Bate tambô, bate tambô (Versos de abertura do Candombe).
}

Tais versos do Candombe apresentam uma versão da alegria subversiva que sobreviveu nas margens de uma narrativa da escravidão que, embora remeta a um passado de sofrimento, também foi marcada por inúmeras formas de resistência vinculadas à força simbólica do tambor e da festa. Nesse sentido, a dimensão lúdica do tambor que traz o "dia de alegria" revela uma cultura festiva que representa uma via marginalizada, porém semiliberta, que preservou aquelas experiências, tradições e conhecimentos que não puderam existir sob a égide de um projeto de modernidade no qual o negro escravizado representava apenas uma força de trabalho subjugada pela dor (COSTA, 2006). Em contraposição a esta versão, o tambor e a alegria operam como forças desestabilizadoras que libertam memórias e imagens que alteram as configurações de um poder cultural hegemônico que se estabeleceu, ao longo dos séculos de regime escravista, a partir da negação, invisibilização e ocultação de todas aquelas perspectivas de mundo que não se enquadrassem na lógica da opressão racial.

Processo semelhante pode ser observado nos pontos que, ao descreverem as mazelas da escravidão, recorrem à figura metafórica do mar como referência às raízes africanas perdidas para a diáspora forçada. Narrando a travessia dos navios negreiros e repensando a África não como coordenada geográfica, mas como mito de origem (LUCAS, 2002), estes pontos irão reposicionar o lugar da escravidão como resultado de uma imposição que não apagou as memórias da liberdade primitiva que permaneceu produzindo um imaginário coletivo que encontrava no passado uma origem emancipada do cativeiro. Uma memória de origem continuamente atualizada e reconstruída a partir da imagem do mar como lócus da passagem que delimitou liberdade e escravidão:

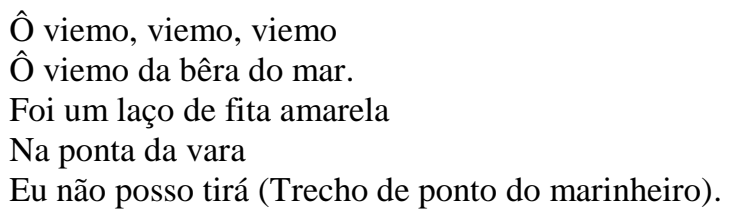


Representada alegoricamente como o "laço de fita amarela" que não pôde ser retirado $^{13}$, a escravidão é concebida neste ponto a partir de sua relação com uma origem na "bêra do mar" que alude à imagem da água como o espaço sagrado que liga o presente e o passado, o mundo dos vivos ao mundo dos mortos (AMBRÓSIO, 1989). 0 mesmo mar que trouxe os europeus e levou ao cativeiro torna-se, assim, o elo com um passado no qual a escravidão nunca foi concebida como uma condição naturalizada, mas como uma imposição que se estabeleceu pela "ponta da vara" da violência sistematizada que possibilitou o tráfico de escravos e o sistema escravista como um todo. Essa concepção é recorrente nos pontos do Açude que, em inúmeros momentos, recorrem à imagem do mar, da praia e das águas como elementos carregados de sentidos simbólicos que remetem à origem, à liberdade e ao próprio Candombe, cuja lenda fundadora se baseia no resgate de Nossa Senhora do Rosário da lapa de um rio através das batidas dos tambores sagrados, tornado-se assim a padroeira dos candombeiros ${ }^{14}$ :

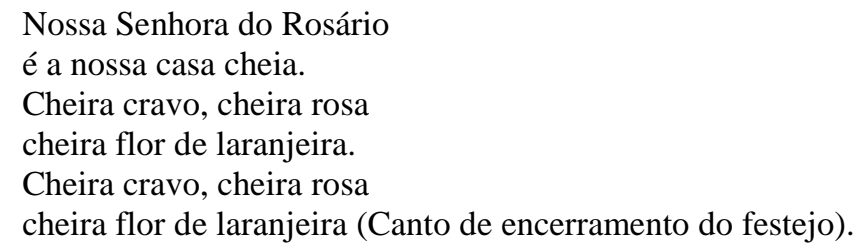

Segundo Martins (1997), é possível encontrar versões dessa lenda que associa a figura de Nossa Senhora do Rosário ao tambor Banto em diversas comunidades afrodescendentes de inúmeras regiões brasileiras. Sua origem é atribuída à aparição e resgate de uma imagem da santa na Argélia e nos relatos de seu culto por volta de 1080 em diversas partes do continente africano (AMBRÓSIO, 1989). Versões que alteram disposições hierárquicas e reconfiguram narrativas religiosas como forma de repensar o mundo a partir de uma perspectiva que tem como ponto de partida a experiência diaspórica que nasceu nos porões dos navios negreiros. Esse tipo de reconfiguração também pode ser encontrado nos Reisados e Congadas que, assim como o Candombe, buscam no mar a origem mítica das raízes africanas que se conecta com a aparição de Nossa Senhora nas águas (LUCAS, 2002). Tal devoção manifesta em tantas

\footnotetext{
${ }^{13} \mathrm{O}$ uso de linguagem cifrada em metáforas e jogos de palavras foi amplamente utilizado durante todo o período escravista como recurso linguístico que permitia aos escravos uma comunicação menos sujeita às punições e repressões de senhores e capatazes.

${ }^{14}$ Segundo a lenda, os homens brancos tentaram em vão colocar a imagem da santa encontrada no rio dentro da igreja, mas ela sempre retornava para as águas. Somente com as batidas dos tambores do Candombe ela teria sido conduzida para terra firme e ali permanecido junto aos negros como protetora e padroeira (MARTINS, 1997).
} 
versões e formatos tem como ponto comum a identificação da santa como uma protetora dos negros que, em algumas narrativas, também aparece como uma santa de pele negra.

Trata-se de uma recodificação cultural de símbolos e perspectivas de mundo que, ao repensarem a origem a partir de outros referenciais, acabam por gerar um verdadeiro encontro de cosmogonias que resistem contra aquelas versões hegemônicas de interpretação da realidade baseadas em lógicas dicotômicas e hierarquizantes. Afinal, se a modernidade enquanto projeto de ocidentalização do mundo se estabeleceu a partir de uma lógica civilizatória binária estabelecida a partir das cisões entre o "eu" e o "outro", o "civilizado" e o “primitivo", o "racional” e o "mítico" (COSTA, 2006); por outro lado, manifestações como o Candombe do Açude parecem criar territórios de fronteiras nos quais não há separação ou distinção clara entre as dimensões da fé e da festa, da reza e da dança, do sagrado e do profano. Conforme Danilo Santos ${ }^{15}$ descreve:

[O Candombe] É uma reza em forma de canto e dança. A noite inteira se formam as rodas e todo mundo pode entrar, fazer seu verso, dançar e cantar junto expressando seus sentimentos daquele momento. Esse é o ponto do Candombe, um abre-caminho e limpa-alma completo que vem dos tambus.

A partir deste relato, podemos observar a grande fluidez e porosidade destes espaços de fronteira característicos de uma roda candombeira em que diversas dimensões da realidade coexistem e se reinventam continuamente. Ela torna-se, assim, um grande desafio aos monopólios dos sentidos instaurados pela hegemonia moderna e suas formas de classificação, sistematização e abordagem do real. Conforme Sodré (2005) analisa, a cultura afrodescendente problematiza questões modernas fundamentais "como a do progresso ilimitado, a da suposta superioridade da História sobre o mito, ou da Modernidade sobre a Antiguidade" (SODRÉ, 2005, p. 10), redefinindo fronteiras e refundando sentidos a partir de um universo simbólico nascido nos espaços da luta pela liberdade. Símbolos de um passado reinventado, que, por sua vez, não buscam se constituir como prova ou afirmação de verdade alguma, mas simplesmente demonstrar que outras perspectivas são possíveis e necessárias para a superação de processos excludentes instituídos justamente através da ocultação de inúmeras vozes e expressões culturais.

\footnotetext{
${ }^{15}$ Danilo Santos representa a nova geração que mantém as tradições legadas pelos antepassados, sendo um dos ritmistas que "puxam" a roda do Candombe e entoam os pontos mais antigos preservados pela comunidade.
} 
Nesse sentido, podemos pensar a cultura candombeira como uma manifestação que, a partir do compartilhamento da experiência sensível da festa, abre caminho para versões de mundo alternativas que reconfiguram significados, percepções e relações de poder (HALL, 1997). Reconfigurações que apontam para novas formas de representação para além daquelas tornadas hegemônicas ao longo de séculos de estigmatização e invisibilização das matrizes culturais afrodescendentes no Brasil. Esta herança discriminatória sobreviveu numa sociedade brasileira profundamente marcada pelo legado opressor do passado escravista que ainda contribui com a perpetuação de uma existência quilombola caracterizada pela exclusão em todas as suas dimensões. Uma existência marginalizada na qual a resistência e a festa representam formas solidárias de uma mesma partilha sensorial de comunidade (RANCIÈRE, 2004) que, por sua vez, inaugura novos modelos de sociabilidade, outras metas coletivas e perspectivas epistemológicas ampliadas: novos olhares capazes de celebrar o presente ao mesmo tempo em que buscam transformá-lo.

\section{Conclusões}

$\mathrm{Na}$ análise da celebração do Candombe realizada pela comunidade Açude Cipó, nos deparamos com a alegria transgressora que faz do tambor e da festa formas lúdicas, performáticas e efusivas de resistência. Elas revelam a dimensão simbólica de narrativas contra-hegemônicas que repensam os mitos de origem, reconfiguram as memórias do passado e recriam as estruturas das fontes religiosas impostas pela lógica colonial sob novas perspectivas. A partir destes outros olhares que se voltam para o mar mítico, as raízes africanas e as divindades católicas, podemos identificar uma cosmogonia que transcende os padrões lógico-discursivos ao apresentar uma concepção de mundo que não separa o mítico do racional, o sagrado do profano, o passado do presente. Nas arestas de tais fronteiras inacabadas, provisórias e em constante movimento, são instaurados espaços de suspensão do real que possibilitam uma partilha do sensorial (RANCIÉRE, 2004) libertadora de memórias, imagens e utopias coletivas.

Trata-se de um imaginário compartilhado profundamente enraizado na consciência histórica que nasce de séculos de lutas contra a exclusão, o silenciamento e o preconceito racial. Lutas marginalizadas que, ao darem vida a performances percussivas, coreográficas e poéticas carregadas de sentidos libertários, acabam por iluminar a cultura candombeira não 
apenas com as memórias passadas da resistência ao regime escravista e às suas formas de opressão, mas também com as experiências de um presente no qual os quilombos brasileiros permanecem socialmente invisibilizados e politicamente negligenciados. Nesse sentido, o Candombe apresenta a face simbólica de uma resistência quilombola que não se limita à reivindicação pelo direito à terra, mas que também envolve as lutas pela sobrevivência e preservação de modos de vida, identidades e crenças, que, por sua vez, demandam uma noção de justiça social ampliada que abarque a tripla dimensão do reconhecimento, da redistribuição e da representação política (GOMES, 2009, p. 18-19).

Uma noção de justiça social que parta de uma visão integrada entre o político e o cultural que remete tanto à pluralidade de que trata FRASER (1992, p. 126) ao pensar as arenas públicas como espaços para a expressão de vozes, estilos e diferenças culturais, quanto à diversidade política de que trata ALVAREZ et al. (2001, p. 33) ao salientar a importância da dimensão cultural para as lutas políticas na América Latina. Trata-se de uma região na qual a cultura tem, historicamente, gerado fatos políticos altamente influentes na luta pela democratização, pela construção de esferas públicas mais inclusivas e pela conquista do exercício da cidadania. Lutas de um Sul multifacetado e dilemático no qual a tradição festiva do Candombe pode representar uma chave de análise fundamental ao dar visibilidade àquelas experiências e práticas que subvertem os padrões cognitivos herdados da colonialidade e da escravidão. Elas representam forças contra-hegemônicas que propõem outras formas de ser e estar no mundo, assim como novas possibilidades de se pensar as lutas políticas afrodescendentes no Brasil cuja dimensão cultural sempre desempenhou um papel crucial.

\section{Referências Bibliográficas}

ALMEIDA, Alfredo W. B. de. Os Quilombos e as Novas Etnias. In: O’Dwyer, Eliane Cantarino. Quilombos: Identidade Étnica e Territorialidade. Rio de Janeiro, Editora FGV, 2002.

ALVAREZ, Sonia E.; DAGNINO, Evelina; ESCOBAR, Arturo (orgs.). Cultura e política nos movimentos sociais latino-americanos (novas leituras). Belo Horizonte: Editora UFMG, 2001.

AMBRÓSIO, Maria Mercês Bonfim. Pedagogia do Rosário- conteúdo educativo da festa. Dissertação de Mestrado, Universidade Federal de Minas Gerais, 1989.

ARAUJO, Ridalvo Felix de; QUEIROZ, Sônia. Cantos dançados no ritual de abertura do candombe da Lapinha. Africanias, n. 6, 2014. 
ARRUTI, José Maurício. A emergência dos "remanescentes": notas para o diálogo entre indígenas e quilombolas. São Paulo: Mana, 1997.

BOBBIO, Norberto; MATTEUCCI, Nicola; PASQUINO, Gianfranco. Dicionário de Política, 11ª edição, v. 1, Editora UNB, 1998.

BOSI, Alfredo. Dialética da colonização. São Paulo: Companhia das Letras, 1992.

BRASIL. Constituição. Constituição da República Federativa do Brasil. Brasília, DF: Senado Federal: Centro Gráfico, 1988.

CAMPOS, Adrelino. Do quilombo à favela. A produção do espaço criminalizado no Rio de Janeiro. Rio de Janeiro: Bertrand Brasil, 2005.

CARNEIRO, Edison. Folguedos Tradicionais. Rio de Janeiro: Conquista, 1974.

Centro de Documentação Eloy Ferreira da Silva (CEDEFES), Projeto Açude Cipó: Disponível em http://www.cedefes.org.br/projetos/acude-cipo. Acesso em: 03 de fev. de 2017.

CEDEFES. Comunidades quilombolas de Minas Gerais no séc. XXI: história e resistência. Belo Horizonte: Autêntica, 2008.

COSTA, Sérgio. Dois Atlânticos: teoria social, anti-racismo, cosmopolitismo. Belo Horizonte: Editora UFMG, 2006.

CRAEMER, Willy de; VANSINA, Jan; FOX, Renée C. Religious movements in Central Africa: a theoretical study. Cambridge University Press, v. 18, n. 4, p. 458-475, 1976.

DIAS, Paulo. A outra festa negra. In: JANCSÓ, István e KANTOR Íris (orgs.). Festa: Cultura e sociabilidade na América Portuguesa. São Paulo: Imprensa Oficial/Hucitec/ Edusp/Fapesp, vol. 02, 2001.

ESCOBAR, Arturo. Mundos y conocimientos de otro modo: el programa de investigación de modernidad/colonialidad latinoamericano. Tabula Rasa, n. 1, p. 51-86, 2003.

FERREIRA, Luís. A diáspora africana na América Latina e o Caribe, Afro-latinos, 2006. Disponível em: http://afrolatinos.palmares.gov.br/_temp/sites/000/6/download/artigos/artigoLuis\%20Ferreira.pdf. Acesso em: 03 de fev. de 2017

FRASER, Nancy. Rethinking the public sphere: a contribution to the critique of actually existing democracy. In: CALHOUN, Craig (ed.) Habermas and the public sphere. Cambridge: MIT Press, p. 109-142, 1992.

GOMES, Lilian Cristina Bernardo. Justiça seja feita: direito quilombola ao território. Tese de Doutorado, Universidade Federal de Minas Gerais, 2009.

GRAMSCI, Antônio. Cadernos do Cárcere: os intelectuais e a organização da cultura. $5^{\mathrm{a}}$ edição. Rio de Janeiro, Civilização Brasileira, 1987. 
GROSFOGUEL, Ramón. Para descolonizar os estudos de economia política e os estudos póscoloniais: Transmodernidade, pensamento de fronteira e colonialidade global, Revista Crítica de Ciências Sociais, 80, p. 115-147, 2008.

GUIMARÃES, Carlos Magno. A negação da ordem escravista: quilombos em Minas Gerais no século XVII. São Paulo: Ícone, 1988.

HALL, Stuart. The work of representation. In: HALL, Stuart (org.) Representation: Cultural representation and cultural signifying practices. London/Thousand Oaks/New

Delhi: Sage/The Open University, 1997.

LUCAS, Glaura. Os sons do rosário: o congado mineiro dos Arturos e Jatobá. Belo Horizonte: Editora UFMG, 2002.

MARTINS, Leda Maria. Afrografias da memória: o Reinado do Rosário no Jatobá. São Paulo: Mazza Edições, Editora Perspectiva, 1997.

MENESES, Maria Paula. Epistemologias do Sul. Revista Crítica de Ciências Sociais, Coimbra, n. 80, p. 5-10, 2008.

MIGNOLO, Walter D. Histórias locais, projetos globais: colonialidade, saberes subalternos e pensamento liminar. Belo Horizonte: Editora UFMG, 2003.

QUIJANO, Aníbal. Colonialidade do poder, eurocentrismo e América Latina. In: A colonialidade do saber: eurocentrismo e ciências sociais. Perspectivas latino-americanas. Edgardo Lander (org). Colección Sur Sur, CLACSO, Ciudad Autónoma de Buenos Aires, Argentina, setembro 2005, p. 227-278.

RANCIÈRE, Jacques. Esthétique et politique. Paris: Galilée, 2004.

SANTOS, Boaventura de Sousa. A crítica da razão indolente. Contra o desperdício da experiência. Porto: Afrontamento, 2002.

SANTOS, Boaventura. A gramática do tempo: para uma nova cultura política. São Paulo: Cortez, $3^{\text {a }}$ ed., 2010.

SANTOS, Boaventura de Sousa; MENESES, Maria Paula (orgs.). Epistemologias do sul. São Paulo: Cortez, 2010.

SARMENTO, Alfredo de. Os Sertões d'África (apontamentos de viagem), Lisboa, 1880.

SILVA, Maria do Rosário Gomes. O potencial emancipatório das festas do tambor mineiro: a dimensão dionisíaca de um Atlântico Negro invisível. Dissertação de Mestrado, Universidade Federal de Minas Gerais, 2014.

SLENES, Robert W.. Malungu, ngoma vem!: África coberta e descoberta no Brasil. Revista USP, São Paulo, n. 12, p. 48-67, 1992.

SODRÉ, Muniz. A verdade seduzida: por um conceito de cultura no Brasil. Rio de Janeiro: DP\&A, 2005. 
TINHORAO, José Ramos. Os Sons dos Negros no Brasil. São Paulo: Art Editora, 1988.

TRINDADE, Cristiano Augusto Ferreira. O Candombe do Açude entre a tradição e a exposição. Dissertação de Mestrado, Universidade Federal de Minas Gerais, 2011. 